\title{
GUERRA HÍBRIDA NO ATLÂNTICO EQUINOCIAL. ÍNDIOS, PORTUGUESES E ESPANHÓIS NA CONQUISTA DO MARANHÃO E GRÃO-PARÁ (1614-1616)
}

\begin{abstract}
Alírio Cardoso*
aliriosj@yahoo.com.br

RESUMO: Durante o governo de Filipe III da Espanha, foi organizada a maior campanha militar ocorrida no norte América portuguesa no período da União Ibérica (1580-1640). Efetivada entre os anos 1614 e 1616, a conquista do Maranhão e Grão Pará foi uma operação bélica internacional que contou com a participação de soldados indígenas, portugueses e espanhóis. Nesta campanha, organizada para dar fim à presença francesa na região, e incrementar a defesa da fronteira Norte, foram utilizadas táticas e armas híbridas, parte indígena, parte europeia. O objetivo deste artigo é refletir sobre a composição da armada portuguesa e a relação dinâmica entre os vários grupos que tomaram parte na conquista lusoespanhola do Maranhão.
\end{abstract}

PALAVRAS-CHAVE: Maranhão; Guerra; União Ibérica.

\section{MARANHÃO NA GUERRA PELO ATLÂNTICO}

Era 23 de agosto, uma ventosa manhã de sábado. Naquele dia do ano de 1614 saiu do porto do Recife uma frota bastante heterogênea cuja missão havia sido planejada meses antes em lugares tão distantes quanto Lisboa, Madrid, Valladolid e Paris. Para aqueles que integravam a frota estava claro que o seu objetivo final, o domínio militar sobre o Maranhão e Grão-Pará, era um dos mais importantes encargos portugueses em tempos da União Ibérica (1580-1640). Os ganhos desta conquista pareciam evidentes, pois no período em que vigorou a união entre Portugal e Castela o extremo norte da América lusa era rota frequente de navegação para perigosos concorrentes europeus, principalmente holandeses, ingleses e franceses. Assim, em 1615 o território português que vai ser conhecido mais tarde como o "Estado do Maranhão e Grão-Pará”, separado em 1621 do Estado do Brasil, foi conquistado aos franceses em uma ação militar

\footnotetext{
* Professor do Departamento de História da Universidade Federal do Maranhão. Doutor em História pela Universidad de Salamanca (Espanha).
} 
financiada pela Coroa espanhola, efetivada por militares luso-pernambucanos, mas que também contou com a participação de outros vassalos do rei Filipe III (1598-1621). ${ }^{1}$

As peculiaridades desta conquista não são de todo conhecidas pela historiografia. Ao contrário do que sugerem alguns trabalhos clássicos, o Maranhão e o Grão Pará não fazem parte do Atlântico Sul, nem mesmo compartilhavam suas rotas mais importantes de navegação. Em todo caso, essa região deve ser considerada a última fronteira entre a América portuguesa e as Índias castelhanas na faixa meridional do Atlântico Norte. Portanto, o mais apropriado seria chamar esta parte do mundo português de Atlântico equinocial, tal como propomos neste trabalho. ${ }^{2}$

Ao fim do século XVI, essa fronteira era quase completamente desconhecida para os portugueses, alimentando uma série de especulações sobre suas possíveis riquezas. A documentação hispano-lusa, a sua maneira, inicia um esforço considerável para definir alguns destes limites espaciais. Não por acaso, entre o final do século XVI e o início do século XVII, as cartas, crônicas e memoriais costumavam identificar estas terras a partir de comparações com a própria América espanhola. Este mesmo acervo documental, principalmente a cartografia da época, admite, muitas vezes, que o Maranhão era fisicamente apartado do Estado do Brasil, lenda cartográfica muito comum entre os séculos XVI e XVII, conhecida como o mito da "Ilha Brasil" (KANTOR, 2007, p. 70-80).

Contudo, o que os documentos do século XVI denominam "Maranhão" é bastante abrangente antes da conquista militar (1614-15). Considera-se "Maranhão" todo o imenso território entre a Capitania do Ceará e as terras castelhanas, correspondente mais ou menos ao que denominamos hoje Amazônia Legal. Em 1535, o Maranhão era uma das capitanias criadas pelo rei D. João III para favorecer o rápido aproveitamento econômico e a defesa do Atlântico português. Assim, as tentativas portuguesas mais célebres de ocupação destas terras, anterior à União Ibérica, foram as iniciativas de João de Barros (1496-1570), famoso historiador da Índia portuguesa. Este donatário tentou chegar ao Maranhão em duas ocasiões, entre 1536 e 1556, ambas malogradas. Segundo Charles Boxer, uma forte inspiração para tais iniciativas de ocupação do norte da América lusa foram as notícias que chegavam a Portugal sobre as conquistas do Peru e da Nova Espanha, e os primeiros relatos das riquezas encontradas 
pelos espanhóis naquelas terras (BOXER, 1980, p. 30). É verdade, entretanto, que na crônica espanhola o rio Amazonas já ganhava certa notoriedade merecendo considerações mais que favoráveis nos escritos de Pedro de Cieza de León (1520-1554), Francisco López de Gómara (1511-1566?), António de Herrera y Tordesillas (15591625), Gonzalo Fernandez de Oviedo y Valdés (1478-1557), ou mesmo do jesuíta José de Acosta (1540-1600), este último autor da Historia Natural e Moral de las Indias $(1590)^{3}$

Região já comentada nos relatos espanhóis, na prática o Maranhão não estava sob o domínio politico-militar luso-espanhol. A jornada de conquista do Maranhão contou com a participação de militares experientes que também prestaram serviço em outros pontos da Monarquia Hispânica. Tal como veremos, um dos aspectos mais interessantes desta operação militar será a adesão voluntária a ela, no interior de um projeto que além de português também era espanhol. Na sua dimensão mais global, a tomada do Maranhão em 1615 pode ser entendida como parte de uma estratégia da Coroa espanhola, interessada em blindar as zonas ao norte do Vice-Reinado do Peru, a rota da prata castelhana, dos principais concorrentes da Monarquia espanhola, as Províncias Unidas dos Países Baixos (CARDOSO, 2012). Entretanto, apesar do onipresente receio de um massivo assalto holandês aos territórios luso-americanos, os portugueses e espanhóis deveriam tratar imediatamente da expulsão dos franceses que já ocupavam a ilha de São Luís desde pelo menos 1612. Na cidade-ilha que será a capital do Estado do Maranhão, os vassalos de Luís XIII já desenvolviam um projeto que não se limitava à construção de simples entrepostos comerciais, prática corrente entre holandeses e ingleses, mas que ganhava a dimensão de uma ocupação fixa e permanente, chamada depois de França Equinocial (1612-1615).

O objetivo deste texto é explorar alguns dados pouco conhecidos sobre a conquista militar do Maranhão e Grão-Pará, principalmente a partir da documentação disponível nos arquivos espanhóis, Archivo General de Simancas (Valladolid), Archivo General de Indias (Sevilha) e Biblioteca Nacional (Madri). Ao mesmo tempo, pretendese enfatizar o caráter múltiplo do projeto de ocupação do norte da América portuguesa que contou com a participação de portugueses de diferentes regiões, índios de diversas nações e inclusive espanhóis de variadas origens. 


\section{NEGOCIANDO COM FRANCESES}

O que na época foi considerado como o "problema francês" ganhou com o passar dos anos outra dimensão na memória historiográfica brasileira. Parte da historiografia redimensionou o confronto entre luso-maranhenses e franceses, exagerando alguns aspectos da presença dos vassalos de Luís XIII na ilha de São Luís, sobretudo no que concerne a sua estrutura militar e a sua organização logística. ${ }^{4} \mathrm{De}$ modo geral, o projeto da França Equinocial tem sua origem relacionada às informações difundidas na Europa através de um navegador que teria visitado as terras ao norte da Capitania de Pernambuco. Seu nome era Charles de Vaux. Este marinheiro francês teria estado no Maranhão, ou a noroeste das capitanias do Estado do Brasil, onde fez contato com índios da nação tupinambá. Em grande medida, as primeiras instruções passadas por Henrique IV e Maria de Médici têm como base as informações prestadas por aquele náufrago (LACROIX, 2002, p. 100-101). Ainda em 1611, a regente determina que o projeto de ocupação desta faixa da América estivesse a cargo de Daniel de La Touche, experiente navegador que nas fontes de época é chamado por seu pomposo título: “Senhor de La Ravardiere". La Touche contava ainda com o apoio de Nicolas Harley e François de Rassilly.

Maria de Médici, que governava a França durante a menoridade de seu filho, Luís, garantiu a esta "Nova França" uma inclinação majoritariamente católica, à diferença do que ocorreu anos atrás com a França Antártica (FORNEROD, 2001, p. 31). A armada francesa de três navios saiu do porto de Cancale, na Bretanha, em março de 1612, fez uma primeira escala na ilha de Fernando de Noronha, passando depois à Capitania do Ceará. No total, a frota era constituída por cerca de 500 homens, transportados nas naus: Regente (homenagem à própria Maria de Médici); Charllote e, ainda, na Saint-anne (BERREDO, 1988, p. 55). Os franceses chegam ao Maranhão nos mês de julho (1612), onde meses depois, na maior das Ilhas da região, fundariam a fortaleza que foi chamada de Saint Louis (VARNHAGEN, 1854, p. 326).

A França não conseguiu manter por muito tempo o sigilo necessário sobre o projeto. Com efeito, já por volta de outubro de 1612 Filipe III, que também governava Portugal, 
já tinha informações concretas sobre as pretensões francesas (VARNHAGEN, 1854, p. 326). No final de 1612, o soberano passou instruções precisas ao governador do Brasil, Gaspar de Sousa, a respeito da jornada de conquista. Em carta régia de 9 de outubro, motivado por informações que chegavam da embaixada espanhola na França, o Monarca Católico enfatiza a necessidade de resolver definitivamente os problemas gerados pela ocupação francesa. ${ }^{5}$ Começaria, então, os preparativos para uma conquista bélica que além de mobilizar o interesse direto do soberano, e a atenção de influentes conselheiros espanhóis, teve o apoio de uma importante fração do poder local lusopernambucano, principalmente ligada à família Albuquerque Coelho (CARDOSO, 2012) .

Como dissemos, parte da historiografia exagerou certos aspectos da estrutura militar construída pelos franceses nas terras do extremo norte da América Portuguesa. Ao contrário do que se pode pensar, o fato que mais chama atenção nas fontes disponíveis sobre a tomada de São Luís não é a violência desenfreada, ou as grandes batalhas entre portugueses e franceses, mas sim os acordos que tiveram lugar nos meses que durou o conflito. No dia 27 de novembro de 1614, uma trégua foi negociada num amistoso banquete, uma mesa que, segundo relata o cronista Berredo, "merecia bem o nome de polida" (BERREDO, 1988, p. 99). Sabe-se também que o capitão português, Jerônimo de Albuquerque, e o general francês, Daniel de La Touche, trocaram diversas cartas durante o conflito, decidindo cancelar as hostilidades até que novas ordens chegassem da Europa. Para tanto, os dois comandantes resolveram enviar agentes às respectivas Cortes para saber dos reis de França e Espanha suas "voluntades, tocante a quien debe quedar en estas tierras del Marañon" (BERREDO, 1988, p. 100). Assim, foi enviado a Paris o capitão Du Pratz, na companhia do português Gregório Fragoso de Albuquerque; e para Lisboa, partiram Diogo de Campos e o oficial francês Maillart (SOUTHEY, 1862, p. 111). Para esta viagem, os portugueses foram obrigados a comprar, pelo valor de 200 mil reis, uma das caravelas francesas, anteriormente tomada na Batalha de Guaxenduba, esta última ocorrida na madrugada do dia 19 de novembro de 1614 e considerado o principal conflito armado luso-francês no Maranhão. ${ }^{6}$

Segundo o acordo, a trégua luso-francesa deveria durar até o fim de dezembro de 1615, quando chegariam novas instruções sobre como deveriam atuar os dois 
comandantes. A trégua estabelecia a libertação imediata dos prisioneiros, incluindo os combatentes indígenas, e também a livre circulação de franceses e portugueses entre ambos acampamentos (BERREDO, 1988, p. 99-100).

$\mathrm{Na}$ Corte, os oficiais enviados do Maranhão entregaram as cartas de Jerônimo de Albuquerque ao Conselho de Portugal. Estas missivas revelam alguns dos detalhes das negociações franco-portuguesas, que incluíam até mesmo a possibilidade de alguns dos “invasores" permanecerem no Maranhão como moradores aliados, no caso de Filipe III considerar conveniente. O capitão Jerônimo de Albuquerque opinava que os franceses poderiam ser de algum proveito, e que o próprio Daniel de La Touche poderia ser convencido a passar para o lado espanhol. ${ }^{7} \mathrm{O}$ Monarca considerou a proposta conveniente, num primeiro momento, pois "se acabaria a empresa sem custar muito sangue", e além disso: "se asseguraria também que o dito Ravardière pela notícia que tem das cousas dessas partes não fosse ocupar outra em que obrigasse a igual ou maior cuidado". 8

Nem todos estavam de acordo com a forma pouco belicosa com que a questão estava a ser resolvida. Esta parecia ser a impressão preponderante no Conselho de Portugal. O marquês de Villa Franca, do mesmo Conselho, foi explícito ao dizer que as pessoas enviadas para expulsão dos franceses "hicieron mal concierto". O marquês da Laguna, por outra parte, recomendou que o francês Maillart, emissário que veio da cidade de São Luís, continuasse detido em Lisboa até que mais reforços fossem enviados do Brasil ao Maranhão. ${ }^{9}$ De modo geral, todos os conselheiros estavam de acordo com que a expulsão dos franceses deveria ser acelerada, pois já chegavam informações de que a França estava disposta a enviar mais 18 navios para socorrer Daniel de La Touche. ${ }^{10}$

Após o retorno dos emissários, tanto da França, quanto de Portugal, a trégua entre as duas Coroas começa a ser definitivamente negociada. Aliado ao esforço diplomático, as iniciativas militares não cessavam. No início de 1615, chegaram reforços enviados pelo governador do Brasil, Gaspar de Sousa, da Bahia e de Pernambuco, comandados pelo capitão Francisco Caldeira Castelo Branco. Estes homens deveriam integrar a frota de sete navios e cerca de 600 soldados que saídos de Olinda chegaram a São Luís em novembro de 1615, capitaneados por Alexandre de Moura (BERREDO, 1988, p. 101-112). 
Finalmente, foi assinado um novo acordo de paz no dia 2 de novembro de 1615, com a entrega definitiva do Forte de São Luís aos portugueses, e a rendição incondicional do general francês. $O$ pedido de indenização feito pelos franceses não teve boa acolhida em Alexandre de Moura, capitão da frota de socorro portuguesa, pois as novas instruções recebidas do reino não falavam nada sobre dar aos vassalos do Rei Cristianíssimo a quantia que pediam, cerca de 2000 ducados. Esta indenização, solicitada por Daniel de La Touche, seria uma compensação pelos investimentos franceses na fortaleza, que na ocasião estaria bem abastecida de diversos produtos, incluindo madeiras, especiarias, armas e munição (FORNEROD, 2001, p. 88-9). Mais tarde, com a formalidade adequada, o Forte de São Luís foi definitivamente entregue aos militares portugueses.

Após a trégua de novembro de 1615, a relação entre franceses e hispanolusos seria mais amistosa. De fato, os franceses tornar-se-iam os primeiros guias dos portugueses no Maranhão. É provável que as notícias mais detalhadas que o capitão Francisco Caldeira Castelo Branco recebeu sobre a rota entre São Luís e o Delta do rio Amazonas tenha sido obra de informantes franceses. A necessidade de fortificar esta rota foi o que deu origem, em 1616, à fundação da cidade de Belém, no Grão-Pará. Além de guias, os franceses também foram os primeiros intérpretes disponíveis na comunicação entre portugueses e índios da nação tupinambá. Por outro lado, nos meses que se seguiram à tomada do Maranhão um personagem passa a atrair cada vez mais o interesse da Corte espanhola. Era o velho Daniel de La Touche, antigo comandante da França Equinocial.

\section{LA TOUCHE, O GENERAL DA DISCÓRDIA}

Militar já bastante calejado, Daniel de La Touche foi um hábil negociador da rendição francesa. $\mathrm{O}$ general soube aproveitar as muitas rivalidades que os portugueses traziam de Pernambuco e Bahia para estabelecer novos e proveitosos acordos. Sabe-se que La Touche, por exemplo, insuflou o antagonismo existente entre os capitães Jerônimo de Albuquerque e Francisco Caldeira Castelo Branco, e tentou tirar algum proveito desta situação. Em determinado momento, a astúcia do general francês irritou o comandante português Alexandre de Moura. Em diversos momentos, Moura confessou 
a má impressão que tinha sobre a condução das negociações luso-francesas. Segundo Moura, o objetivo do astuto general francês não era outro senão ganhar tempo. ${ }^{11}$ Sabe-se também que La Touche tirou proveito de uma clara deficiência da armada lusa: a sua dispersão hierárquica. No total, entre frota de reconhecimento (capitaneada por Jerônimo de Albuquerque), frotas de socorro (uma liderada por Francisco Caldeira Castelo Branco, e a principal por Alexandre de Moura), o comando muitas vezes não estava claramente definido. A chegada das novas ordens com Alexandre de Moura apenas agravou a situação. Essa indefinição no comando português, sem falar no declarado risco de motim entre os oficiais lusos, foi a grande vantagem de La Touche em toda a negociação de paz. ${ }^{12}$

O receio luso-espanhol em torno da figura de Daniel de La Touche transcendia a questão da ocupação francesa. Pelo que informavam os comandantes portugueses, o general francês era um especialista em navegação maranhense, prático em rotas completamente desconhecidas para os marinheiros lusos. Por isso, sua liberdade passa a ser considerada negócio de Estado por espanhóis e portugueses. Após o fim do conflito, o "senhor de La Ravardière" foi enviado como prisioneiro de Alexandre de Moura para entrevistar-se com Gaspar de Sousa, então governador do Brasil, que aguardava em Pernambuco. Após uma breve permanência naquela capitania, temporariamente convertida em capital do Estado do Brasil, Daniel de La Touche foi enviado a Lisboa, permanecendo na Torre de Belém à disposição das autoridades hispano-lusas. Resolvida a questão no Maranhão, a pergunta passa a ser: o que fazer com o general francês? A negociação a respeito, realizada em Portugal, Espanha e França é relativamente bem documentada. O tema também passa a ser constante nas reuniões do Conselho de Portugal. O governo espanhol tinha de responder às recorrentes demandas francesas pela libertação de La Touche. Na prisão, o general francês entrevistou-se com o próprio marquês de Alenquer, D. Diego de Silva y Mendoza, que assim descreveu as suas impressões a respeito do antigo comandante da França Equinocial:

Andando yo con este cuidado me vino a ver estos días el señor de la Ravardière que es el general que el Rey de Francia envió al Marañón y entregó a Vuestra Majestad la parte que allí tenia y fue traído a esta Corona según el dice por trato, y según otros porque no se podía defender, y pidíome pasaporte para poder se embarcar en uno de los navíos franceses que estaban en este puerto, y aunque no se le pude negar por [escuchar] quejas del Rey de Francia todavía repare en que si este hombre se iba no haría ninguna falta la noticia a que se enviaba a 


\begin{abstract}
buscar con los dos capitanes: porque el la tiene muy grande así de las cosas de este Reino, de la situación de los castillos, flaquezas, y padrastos de ellos y sabe que tienen apeada la artillería y ninguna gente para su defensa: y todas las otras circunstancias que el más inteligente puede penetrar, es también muy platico de las cosas del Brasil, y particularmente del Marañón y el Pará: porque a medido a palmos aquella tierra y con las naciones de ella tiene particular comunicación y conocimiento: y aunque no le tengo por hombre de manos ni corazón es tan experimentado y de tan buena cabeza que me da cuidado su salida de aquí: mayormente con la nueva que se ha tenido de que el Pará está levantado, pues podría volver allá y darnos el cuidado que nos dio en el Marañón". ${ }^{13}$
\end{abstract}

As mesmas preocupações eram compartilhadas por outros membros do Conselho de Portugal. Além da possibilidade de reedição da França Equinocial, as autoridades hispano-lusas temiam outras consequências da libertação do general francês. Com efeito, nos últimos anos da década de 1610 começavam fortes especulações sobre possíveis acordos envolvendo Daniel de La Touche e os Países Baixos. ${ }^{14}$ Segundo se dizia, La Touche alimentava o desejo de voltar a governar o Maranhão, agora com o apoio militar holandês. ${ }^{15}$

Outro tema sempre preocupante era o possível apoio que La Touche parecia nutrir entre as lideranças indígenas do Maranhão. Em 1617, ano em que ocorreu um grande motim intertribal, mas principalmente tupinambá, na Capitania de Cumã (atual Alcântara), as autoridades hispano-lusas estavam em alerta máximo quanto à possibilidade de uma onda antilusitana nas capitanias do Maranhão e Grão-Pará. D. Diego de Cárcamo, espanhol de Córdoba, que havia sido escolhido pelo rei como o primeiro governador do Maranhão, aliás, algo inédito na América portuguesa, conta que Daniel de La Touche, que aparentemente estava enfermo na Torre de Belém, quando soube dos motins indígenas que estavam ocorrendo do outro lado do Atlântico: "levantou da cama e se foi banquetear com os franceses companheiros que haviam estado com ele na dita conquista". ${ }^{16}$ Por todos estes motivos, as autoridades portuguesas e espanholas tinham claro que La Touche era perigoso demais para retornar ao Maranhão. Em função de sua experiência, supostas alianças na Europa e acordos prévios com as lideranças indígenas, $\mathrm{La}$ Touche era considerado o homem potencialmente mais perigoso para os interesses hispano-lusos na região.

Por volta de 1619, os protestos do reino de França aumentavam, ao ponto de Filipe III solicitar ao marquês de Alenquer a exposição dos motivos que ainda justificavam a permanência do general francês na Torre de Belém. ${ }^{17}$ Em resposta, o 
vice-rei de Portugal insiste no argumento de que a libertação de La Touche seria bastante inconveniente aos interesses espanhóis por ser o general francês "persona que puede dar cuidado porque las conquistas de Portugal y Indias de Castilla las sabe mejor que los que más cursan en ellas". ${ }^{18}$ Outra vez, Daniel de La Touche tentou tirar proveito da situação. Sabemos que o general francês tinha correspondência com autoridades de seu país natal, e que em ocasiões tentou obter favores inclusive da própria princesa Ana de Áustria. ${ }^{19}$ Além disso, mesmo preso na Torre de Belém, La Touche pretendia garantir para si a indenização que, em 1615, lhe foi negada pelo capitão Alexandre de Moura, referente à entrega do Forte de São Luís. Também é possível que La Touche ainda alimentasse a expectativa de voltar ao Maranhão, com ou sem auxílio holandês. ${ }^{20}$

Claramente, a questão mais importante nas negociações com o reino francês sobre a libertação do Senhor de La Ravardière são as referências a uma possível trama franco-holandesa, com a união de armas entre huguenotes franceses e representantes das Províncias Unidas. ${ }^{21}$ Por outro lado, as especulações a respeito do suposto acordo que La Touche teria com os holandeses, embora nunca comprovadas, e mesmo desqualificadas pelo embaixador espanhol na França, D. Iñigo de Cárdenas, não deixavam de preocupar as autoridades espanholas. Por isso, era mais que compreensível a cautela exagerada com relação ao general francês.

Nas fontes disponíveis não está de todo claro o destino do general Daniel de La Touche. O que se sabe é que a especulação acerca de um possível acordo militar francoholandês revelou-se pouco crível nos últimos anos da década de 1620. Da mesma forma, não há registro de qualquer intervenção direta de La Touche em qualquer tentativa de reedição da França Equinocial, como temia a burocracia hispano-lusa. Por outro lado, há poucas dúvidas de que a França Equinocial representou uma tentativa efetiva de ocupação civil-militar da fronteira entre o Brasil e as índias castelhanas. Os franceses não tinham como único objetivo a instalação de feitorias, ao modo do sistema inglês e irlandês.

Entretanto, não se pode considerar a conquista do Maranhão como uma resposta automática e improvisada à possibilidade de ocupação francesa do norte da América lusa. Os projetos hispano-lusos de conquista desta região embora apressados pela França Equinocial não foram unicamente motivados pela presença francesa, como veremos. De modo geral, os motivos para a conquista do Maranhão e Grão-Pará são 
muito mais complexos do que se costuma pensar e envolve interesses internacionais, mas também locais.

\section{OS VÁRIOS PROJETOS}

Se não considerarmos a expedição de Martim Soares Moreno, que em 1613 navegou para o Maranhão por ordem de Gaspar de Sousa, o primeiro ensaio geral para a conquista das novas terras ocorreria em 1603. Foi a jornada ao Ceará organizada pelo açoriano Pero Coelho de Sousa, em tempos do Governador Diogo Botelho (1602-1607). É possível, se acreditarmos no relato feito pelo sargento-mor Diogo de Campos, que Pero Coelho tivesse pretensões de chegar ao Maranhão pela via terrestre, atravessando a perigosa serra de Ibiapaba, que tinha fama de ser um dos piores núcleos de tapuias rebeldes daquela parte da América portuguesa. Segundo o mesmo Diogo de Campos, esta expedição contaria com 80 soldados portugueses, 800 índios flecheiros, divididos em dois “caravelões", um cálculo que hoje considera-se exagerado.

De qualquer forma, na expedição de Pero Coelho já é possível encontrar certos elementos que estariam presentes também na jornada ao Maranhão: o investimento particular, sem grandes custos para a Fazenda Real; a necessidade de apoio militar nativo; e as primeiras tentativas de negociação com os índios principais. Foi também nesta expedição que os portugueses conheceram de perto o problema do fluxo de barcos piratas na rota entre o Maranhão e as Guianas.

A expedição de 1603 contava com a presença de um jovem Martim Soares Moreno que, dez anos depois, seria um dos primeiros portugueses a fazer o caminho por via marítima entre o Estado do Brasil e o Maranhão. ${ }^{22}$ Um dos resultados imediatos da jornada ao Ceará foram as informações prestadas por Diogo de Campos que, entre 1604 e 1606, realizou viagens à Espanha para informar pessoalmente Filipe III sobre a situação da presença "estrangeira" naquela costa. Estas informações foram fundamentais para o planejamento da conquista, entre 1612 e 1614.

A conquista do Maranhão, apesar das instruções de Filipe III, não escapou de uma certa improvisação. Em certa ocasião, o próprio Diogo de Campos reclamou que a armada de Sua Majestade contava, no início, com apenas 3 mil alqueires de "farinha da terra" (mandioca), e não levava quantidade suficiente de carne e azeite, nem tinha 
cirurgião-barbeiro a bordo, além de contar com poucos soldados portugueses. Aliás, foi pela falta de recursos apropriados que a jornada do Maranhão ganhou o título de "milagrosa". Por isso, as chaves para entender o sucesso desta operação são: em primeiro lugar, a participação indígena; e, em segundo lugar, a adesão de particulares que embarcaram em Pernambuco por sua própria conta. Na última hora, graças a uma carga que chegou ao Recife, proveniente do Rio de Janeiro, a jornada acrescentou aos seus bastimentos mais 6 mil alqueires de farinha, 100 arrobas de peixe, 20 quintais de pólvora, quantidade de arcabuzes, mosquetes, chumbo e morrão.

Muitas dúvidas e problemas foram resolvidos ao longo do percurso. A maior de todas as preocupações recaia sobre o número insuficiente de índios que formavam a milícia de apoio. Entretanto, outras questões como a quantidade inadequada de barcos, ou a pouca ração de guerra disponível não deixavam de tirar o sono dos oficiais. A escolha de Jerônimo de Albuquerque como comandante da armada portuguesa pareceu a mais acertada aos olhos dos contemporâneos, em função da fama que tinha este militar português de ser fluente no estilo de guerrear dos índios e falante contumaz das suas línguas. O comando deveria ser compartilhado, entretanto, com Diogo de Campos, conhecido sargento-mor do Estado do Brasil.

No momento em que os preparativos para a jornada estavam quase concluídos, não se sabia o paradeiro do capitão Martim Soares Moreno, responsável pela expedição de reconhecimento em 1613. Desta forma, a armada lusa resolveu partir sem o seu mais experiente navegador, um dos únicos que conhecia o rumo a seguir. Assim, a jornada foi dividida em duas partes. A primeira, comandada por Jerônimo de Albuquerque, deveria esperar na Capitania do Rio Grande, com homens, barcos e bastimentos; a segunda força, a principal, foi comandada pelo sargento-mor Diogo de Campos. O Rio Grande, como veremos mais tarde, era uma fortaleza estratégica pela suposta garantia de adesão de índios flecheiros. Ou, assim pensavam os portugueses.

Tal como já foi dito, a força militar principal saiu do porto do Recife no dia 23 de agosto de 1614. Contando todos os soldados, aqueles que partiram do Recife e os demais que esperavam no porto do Rio Grande, a armada teria um número bastante reduzido de soldados brancos, cerca de 300 homens, divididos em cinco caravelões. No Rio Grande, as milícias voltariam a separar-se. Uma parte resolve fazer o caminho até a fortaleza do Ceará por terra; os demais fariam o percurso pelo mar. Esta escolha tática ilustra bem o diferente perfil dos comandantes da jornada: de um lado estava o 
sertanista Jerônimo de Albuquerque, acostumado com as práticas da guerra indígena; de outro, Diogo de Campos, mais adepto do modo convencional da guerra europeia. É justo dizer que a conquista do Maranhão foi acima de tudo uma operação híbrida, em que os recursos da guerra convencional deveriam caminhar lado a lado com as estratégias da guerra nativa, pois até mesmo a sobrevivência material da tropa dependia de índios aliados.

A ocupação do extremo norte da América portuguesa cumpria certos objetivos gerais no interior da nova situação político-militar gerada com a União Ibérica. Sabe-se que a iniciativa militar pernambucana era apenas uma das opções para resolver o problema francês. De fato, para a expulsão definitiva dos franceses surgiram na época outras soluções possíveis. Em 1615, por exemplo, o conde de Salinas, futuro marquês de Alenquer, defendeu a proposta de enviar soldados do Chile para socorro aos portugueses que lutavam no Maranhão. ${ }^{23} \mathrm{~A}$ mesma proposta vai ser objeto de algumas apreciações pelo Conselho de Portugal até demonstrar-se inviável pelos problemas logísticos que acarretava. ${ }^{24}$

Em todas as etapas da conquista, planejamento na Europa e no Brasil, envio de forças auxiliares, combate efetivo contra os franceses, houve a participação de soldados e oficiais espanhóis. Fato pouco estudado pela historiografia, a conquista do Maranhão deve ser analisada também a partir do impacto da integração dos portugueses na Monarquia Hispânica, e de espanhóis nos negócios dos covassalos lusos. A participação espanhola não se resumiria, por outro lado, ao aspecto militar. Como já dissemos, Filipe III já havia nomeado a D. Diego de Cárcamo, espanhol natural de Córdoba, como o primeiro governador do Maranhão. ${ }^{25} \mathrm{O}$ primeiro governador eleito do Maranhão era filho de Pedro de Tovar. Naturalizado português, era casado com dona Antónia de Vilhena, e já tinha vínculos importantes com a burocracia lisboeta (BERREDO, 1988, p. 137-8). Na condição de governador do Maranhão, Cárcamo participou do planejamento luso-espanhol para a defesa da fronteira norte, opinando também sobre diversos outros temas. ${ }^{26}$

Em outros documentos do ano de 1621, Cárcamo ainda é considerado "capitão general" do Estado do Maranhão, até ser substituído por outros candidatos prévios, e finalmente pelo luso-pernambucano Francisco Coelho de Carvalho que chegou à cidade de São Luís apenas em 1626. Não estão totalmente claros os motivos da desistência de Cárcamo, ainda mais em razão do silêncio de cronistas minuciosos como Berredo ou 
Bethendorf. Em abril de 1621, um “aviso anônimo" enviado ao Conselho de Portugal alega que o virtual governador já estaria em idade avançada, ao mesmo tempo em que sugere sua ligação com o regime anterior à União Ibérica. ${ }^{27}$

Sem ignorar o esforço diplomático, do qual participa indiretamente o próprio Diego de Cárcamo, estava claro que a expulsão dos franceses dependeria de outros fatores, entre eles a capacidade de aliança com as nações indígenas da região. Os portugueses sabiam que não era uma boa ideia ir à guerra sem índios. Por isso mesmo, a jornada ao Maranhão deveria incluir guerreiros nativos das capitanias do Norte do Estado do Brasil, sem os quais não seria possível expulsar os franceses, nem garantir a proteção da região contra a concorrência europeia.

\section{UMA GUERRA INDÍGENA}

A participação indígena existiu em diversos níveis: no transporte fluvial e terrestre; na intermediação junto a outros grupos nativos; e nas escaramuças contra os regimentos franceses, que também contavam com um grande número de índios flecheiros nas suas filas. A primeira expectativa era reunir cerca de 1000 guerreiros, que deveriam ser arregimentados ao longo do caminho mediante diferentes mecanismos que incluíam a negociação direta com os chefes nativos, os principais. Sobre o tema, a documentação é bastante fragmentada. Faltam dados mais seguros sobre o número exato de índios envolvidos, sobre as nações que forneceram guerreiros para esta empresa, e sobre o papel reservado aos líderes militares nativos, problemas recorrentes na História Indígena brasileira (MONTEIRO, 2001).

Os índios eram os únicos guias disponíveis para esta rota. O próprio governador do Brasil, Gaspar de Sousa, quando esteve em Olinda coordenando de perto a jornada do Maranhão considerou que a forma mais eficiente de proteger a região seria evitar qualquer contato entre índios e "estrangeiros". Os portugueses temiam a possibilidade de que "piratas" pudessem obter a ajuda de guias nativos na passagem furtiva entre o Norte do Brasil e o Maranhão. ${ }^{28}$ Entre outras coisas, sabia-se que parte daquela navegação, sobretudo os trechos fluviais, só poderia ser feita com o auxílio de canoas nativas. Em todo caso, aqui é necessário levar em conta o fato de que poucos portugueses conheciam realmente o caminho. Na sua famosa jornada de 1613, por 
exemplo, o capitão Martim Soares Moreno levou consigo guias indígenas, "práticos naquela costa" do Maranhão, com quem havia estabelecido contato ainda nas terras do Ceará. $^{29}$

É possível dividir o corpo de apoio indígena em cinco grupos: principais, flecheiros, remeiros, línguas e, ainda, os que tratavam exclusivamente dos mantimentos, como era o caso das mulheres que acompanhavam a jornada. Esta divisão não é muito precisa e sabemos que, na verdade, um único índio poderia desempenhar distintas funções. Não é tarefa fácil estimar o número de guerreiros recrutados. Sobre o tema, não se pode fazer mais que aproximações baseadas nos dados fornecidos pela documentação portuguesa e, eventualmente, francesa. Nesta época, a fortaleza do Rio Grande, uma das escalas mais importantes da jornada, contava com uma quantidade relativamente pequena de índios flecheiros. No dia 28 de agosto de 1614 foi feito um censo sobre o número de índios disponíveis naquela fortaleza. Pelos cálculos do sargento-mor, Diogo de Campos, havia apenas 234 flecheiros, liderados por 12 principais que representavam diferentes nações. ${ }^{30}$ Contudo, esta estimativa não incluía, ainda, aqueles que foram recrutados no Ceará. Na chegada à Capitania do Ceará, o próprio Jerônimo de Albuquerque, em companhia de Belchior Rangel, língua português natural do Rio de Janeiro, estabeleceram contato com os índios da região e tentaram convencer os principais a participar da jornada (BERREDO, 1988, p. 71-9).

Nas fontes sobre a jornada, consta pouca informação também sobre os nativos que passaram para o lado português já no Maranhão, em pleno calor da luta. Os portugueses estavam seguros de conseguir vantajosas alianças explorando a rivalidade entre índios tupinambá, da ilha do Maranhão, e os índios da nação tremembé, da parte continental. ${ }^{31}$ Por isso, parece pouco provável a mítica inferioridade numérica na Batalha de Guaxenduba, muitas vezes alardeada como signo da capacidade militar lusa, ocasião em que algumas centenas de portugueses derrotaram cerca de 2000 índios aliados dos franceses. ${ }^{32}$ Ainda na primeira jornada, no dia 28 de setembro de 1614 , foi realizado um segundo censo para avaliar o número de índios reunidos no Ceará. Com alguma frustração, o sargento-mor Diogo de Campos constata que, mesmo contando com a experiência de Jerônimo de Albuquerque, e a influência dos aliados principais, a contribuição do Ceará não passava de 220 guerreiros, a maior parte provavelmente da nação tabajara. Ao mesmo tempo, os portugueses tiveram de lidar constantemente com o perigo da deserção entre os seus quadros nativos. ${ }^{33}$ 
A segunda armada, saída de Pernambuco em outubro de 1615, era bem maior. Sob o comando de Alexandre de Moura, contava já com a presença do afamado Martim Soares Moreno e com cerca de 900 homens. Deste total, mais uma vez não há informações precisas sobre a quantidade de flecheiros. Sabe-se, na comparação com jornadas semelhantes, que o número de guerreiros indígenas era quase sempre bem superior à quantidade de combatentes brancos. Não há indícios para considerar aqui o contrário. Tal como na primeira jornada, nesta segunda expedição a tática dos portugueses consistia em arregimentar o maior número possível de nativos ao longo do caminho, utilizando para este fim o poder de convencimento dos línguas (BERREDO, 1988, p. 71-9).

Para obter a adesão nativa, a comunicação não deveria ser um problema. Os línguas trazidos de Pernambuco, Rio Grande e Ceará resolveriam em parte a questão. As duas jornadas ao Maranhão contavam também com portugueses falantes de línguas indígenas, principalmente: Jerônimo de Albuquerque, Melchior Rangel e Martim Soares Moreno. ${ }^{34} \mathrm{O}$ problema da comunicação também deveria ser solucionado com os missionários jesuítas que acompanharam a armada. Do lado francês, a comunicação com os nativos já estava em estágio avançado, com os serviços do Mons. Tureou, língua-mor do exército do Rei Cristianísssimo. ${ }^{35}$ Portugueses e espanhóis também tinham informações que indicavam que o mesmíssimo general, Daniel de La Touche, era um prático nas línguas indígenas, habilidade que teria garantido aos franceses a adesão de muitos grupos nativos. ${ }^{36}$ De fato, soube-se depois que, no convento dos padres capuchinhos de São Luís, franceses e índios tupinambá costumavam celebrar reuniões onde "aprendiam as línguas uns dos outros". 37

Uma das grandes preocupações do exército francês era exatamente a eficiência que demonstravam os línguas portugueses no recrutamento de novos guerreiros. Esta foi provavelmente uma das chaves da vitória portuguesa. Não por acaso, um dos artigos do tratado de paz de 27 de novembro de 1614, estabelecido para que ambos grupos obtivessem novas instruções nas suas respectivas Cortes, proíbe expressamente que os línguas portugueses tivessem qualquer contato com índios da ilha do Maranhão ou do continente (Tapuitapera). ${ }^{38} \mathrm{Na}$ mesma ocasião, Filipe III, informado sobre a importância destes mediadores nativos, decidiu que o governador a ser escolhido para assumir o Estado do Maranhão deveria ser "pessoa que tenha experiência do gentio". 39 
Uma das responsabilidades dos línguas, sejam eles brancos ou não, era a negociação com os índios principais. De fato, ao longo do percurso, sobretudo entre o Rio Grande e o Ceará, foram recrutados índios de diversas nações sempre acompanhados dos seus respectivos chefes militares (ver quadro). Dentre os principais que integraram a armada portuguesa, alguns deles mereceriam destaque na documentação, quer seja pelo recrutamento de novos guerreiros, a exemplo dos irmãos Camarão e Jacaúna, quer seja pela capacidade bélica demonstrada em campo de batalha, como ocorreu no caso do principal dos tabajara, Mandiocapúa, cujas qualidades impressionaram a Diogo de Campos. ${ }^{40}$ Por outra parte, esta negociação nem sempre funcionou como os portugueses esperavam, a julgar pelo que ocorreu com os índios do Ceará, sobretudo aqueles liderados pelo principal Diabo Grande da serra de Ibiapaba, que retirou na última hora seu apoio militar à armada. ${ }^{41}$

A participação indígena na conquista do Maranhão pode ser considerada, para as capitanias de Rio Grande, Ceará, Maranhão e Grão-Pará, como um dos ensaios prévios para a guerra hispano-holandesa na região. Em ambos casos, algumas estratégias são recorrentes: a negociação com os principais; a adoção de táticas militares híbridas, com acentuado valor atribuído ao sistema indígena de emboscadas; e a valorização de militares portugueses habituados com o trato nativo. Ao mesmo tempo, os próprios índios estavam cada vez mais conscientes de que os portugueses eram completamente dependentes das milícias nativas. Com efeito, muitos destes índios reconheceram vantagens nesta situação, obtendo ganhos coletivos ou individuais. De qualquer forma, continua a ser um desafio estabelecer o número de índios que saiu do Estado do Brasil para combater franceses em nome de Filipe III, principalmente em função da falta de cifras confiáveis. 


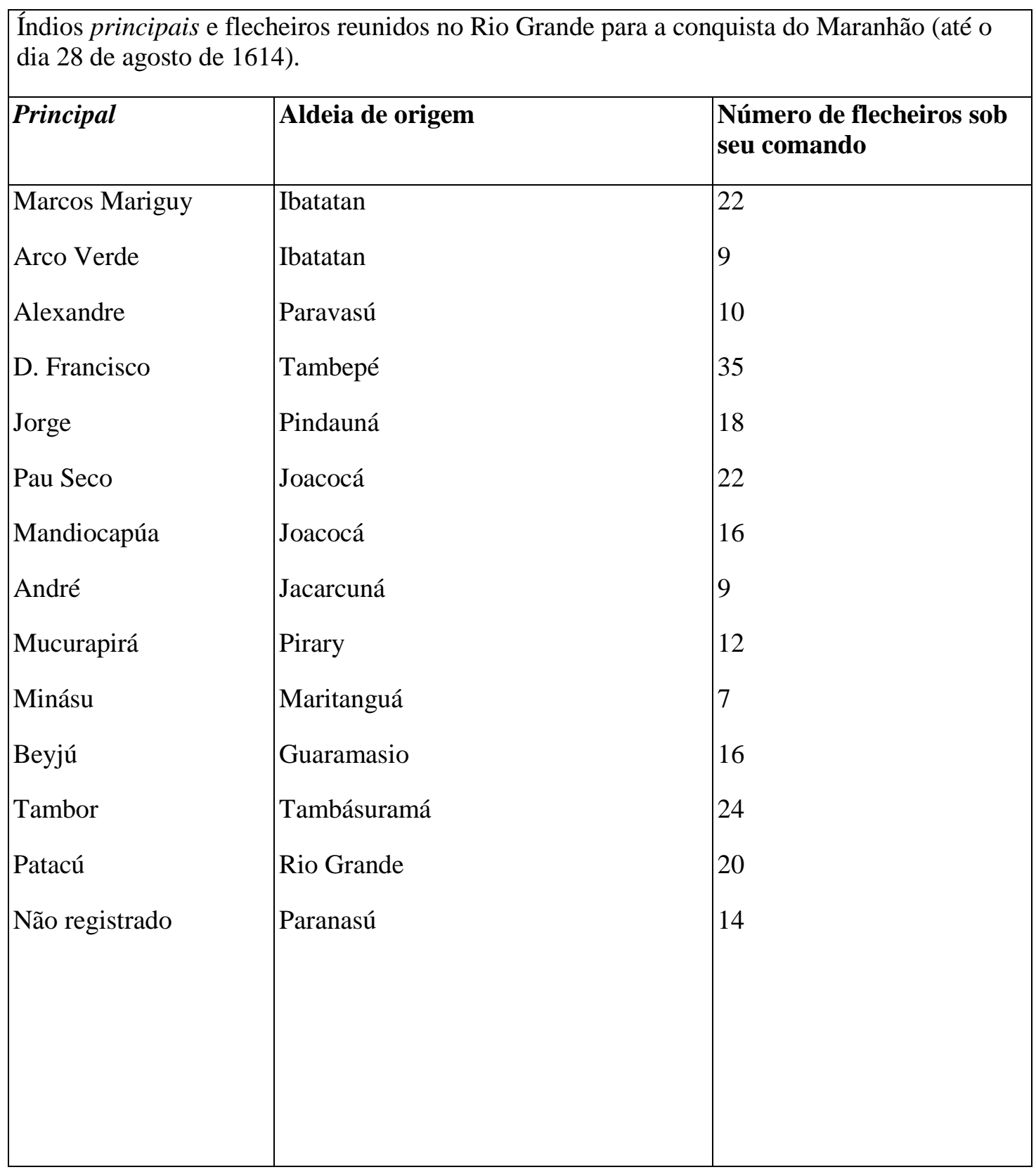

FONTE: "Jornada do Maranhão por Diogo de Campos Moreno Sargento-Mór do Estado do Brazil”, p. 229-30.

Em geral, a conquista do Maranhão foi rapidamente incorporada à economia das mercês da Monarquia Hispânica. Com efeito, diversos oficiais pedem nos anos que se seguiram à rendição francesa cargos, honras e recompensas variadas. Desde os filhos do capitão-mor Jerônimo de Albuquerque, ${ }^{42}$ ou do governador Gaspar de Sousa ${ }^{43}$, até índios principais tabajara ou nhengaíba; desde cargos administrativos de menor expressão até comendas das Ordens Militares, todos os envolvidos passam a inundar a 
burocracia luso-espanhola na busca por sua própria memória da guerra aos franceses. ${ }^{44}$ Com o tempo, a própria historiografia criaria um panteão formado por nomes como: Jerônimo de Albuquerque, Diogo Moreno, Martim Soares Moreno, Alexandre de Moura, suprimindo por vezes a participação decisiva das lideranças indígenas: Arco Verde, Mandiocapúa, Marcos Mariguy, entre muitos outros. Aqui parece residir uma diferença em relação à memória dos Restauradores pernambucanos, cuja participação indígena também seria decisiva e mais sólida do ponto de vista das efemérides. ${ }^{45}$ Por fim, não seria exagerado comparar a conquista do Maranhão, no contexto da união de Coroas, com a famosa "jornada dos vassalos" da Bahia, de 1625. Nos dois casos, temos diversos projetos particulares convergentes sobre um mesmo escudo, o Habsburgo, mas que ainda conservavam a diversidade própria da guerra praticada nas terras tropicais. ${ }^{46}$

\section{HYBRID WAR IN EQUINOCTIAL ATLANTIC. INDIANS, PORTUGUESE AND SPANISH IN THE CONQUEST OF THE MARANHÃO AND GRÃO- PARA (1614-1616).}

ABSTRACT: During the reign of Philip III of Spain, was organized the most important military expedition occurred in the north of Portuguese America in the period of the Iberian Union (1580-1640). Effected between the years 1614 and 1616, the conquest of Maranhão and Grao-Pará was an international operation with the participation of indigenous soldiers, Portuguese and Spanish. In this campaign, organized to end the French presence in the region and increase the defense of the northern border, using hybrid tactics and weapons, part Indian, part European. The objective of this paper is to discuss the composition of the Portuguese fleet and the dynamic relationship between various groups who took part in the conquest of the Spanish-Portuguese Maranhão.

KEYWORDS: Maranhão; War; Iberian Union.

\section{NOTAS}

1 Sobre o impacto da união de Coroas para o antigo Estado do Maranhão, ver: CARDOSO, 2011, p. 317-338.

2 A noção de "Atlântico Equatorial" já havia sido proposta pelo Doutor Rafael Chambouleyron. Ver CHAMBOULEYRON, 2006, pp. 79-114. Sobre a relação entre Maranhão e o Atlântico Sul, ver: CARDOSO, 1984. ALENCASTRO, 2000. Para uma versão diferente sobre a mesma questão, ver: CHAMBOULEYRON, 2005.

${ }^{3}$ Ver por exemplo: REIS, 1993, p. 26. 
${ }^{4}$ Sobre o projeto francês conhecido mais tarde como França Equinocial, ver: DAHER, 2007. LACROIX, 2002. MEIRELLES, 1982. PIANZOLA, 1992. FORNEROD, 2001. OBERMEIER, 2004, p. 33-50.

5 "Instrução para Gaspar de Sousa, guovernador do Brasil, sobre a conquista do Maranhão". Lisboa, 9 de outubro de 1612. Cartas para Álvaro de Sousa e Gaspar de Sousa (1540-1627). Lisboa: CNCDP/MRE, 2001, doc. 58, p. 159. Doravante será citado como: $C A S G S$.

${ }^{6}$ Sobre a batalha, ver: "Para o governador do Brasil". Madrid, 21 de março de 1615, CASGS, doc. 149, p. 254.

7 "El S ${ }^{\mathrm{r}}$ Duque de Lerma.//E en cartas que el Albuquerq escrivia al Sosa le decía q. començaria a plantar mantenim ${ }^{\text {tos }}$ con simientes q. le avia offrecido Rabardieri y q. entendía seria fácil reducille al $\left[\operatorname{ser}^{\circ}\right]$ de $\mathrm{su}^{\mathrm{d}}$, y q. muchos franceses le avian dado palavra quedarían allí por moradores / el conss ${ }^{\circ}$ dice q. conside=rando que los franceses pueden ser allí de provecho si seganan, ordeno luego q. se escriviese al Sosa e tregandole los fuertes q. franceses tienen y dexando las armas los admitan en servi ${ }^{\circ}$ de $\mathrm{Su} \mathrm{M}^{\mathrm{d}}$ y los señale tierras en [diban], adbirtiendo q. los divida y si posible no quede ningúno en el Marañon." 2 de mayo de 1615, Archivo General de Simancas, Estado (Portugal), 260. Doravante será citado como: AGS.

8 "Para o governador do Brasil". Madrid, 5 de abril de 1615, CASGS, doc. 158, p. 263. Atualizamos a ortografia.

9 "El Cons" de Estado a 2 de abril de 1615 con la cons ${ }^{\text {ta }}$ inclusa del de Portugal tocante alo del Rio Marañon" 2 de abril de 1615. AGS, Estado (Portugal), 260.

10 "La consulta inclusa del Consejo de Portugal sobre el aviso q. se ha tenido de 18 navios q. se arman en francia para socorrer a los franceses q. están en el Marañon, manda $\mathrm{Su} \mathrm{M}^{\mathrm{d}}$ que luego se vea en el Consejo de estado y sele avise loq. ${ }^{\circ}$ pareziere Dios q. ${ }^{\mathrm{d}}$ a [sua] de Pal. ${ }^{\circ}$ a 28 de mayo de 1615". AGS., Estado (Portugal), 260.

11 "RELATORIO de Alexandre de Moura sobre a expedição a ilha do Maranhão e expulsão dos francezes". Lisboa, 24 de outubro de 1616. Annaes da Biblioteca Nacional do Rio de Janeiro, vol. 26, (1905), vol. 26, p.197. Doravante será citado como: ABNRJ

12 "TRESLADO do requerimento que fizerão alguns oficiaes e soldados desta Conquista ao capitão mor Francisco Caldeira Castellobranco a efeito, de que fosse adjunto, e collega do Capitão mor Hieronimo de Dalbuqueque". ABNRJ, vol. 26, pp. 206-229.

13 “Carta del Marques de Alenquer a el Rey sobre los franceses en el Marañon”, 11 de febrero de 1619. AGS, Estado K (Francia), 1431, A2.

14 “Al Marques de Alenquer". 19 de febrero de 1620. AGS, Estado (Portugal), 2710.

15 “Avis anonyme - Nouvelle de Portugal”. 28 (?) de abril de 1621, [sin firma]. AGS, Estado K (de Francia) 1431, A42, nos . 116-143.

16 Carta de Don Diego de Carcamo. Lisboa, [sin fecha] 1620, [Firma: Don Di de Carcamo]. AGS, Estado K (Francia), 1477.

17 "Juan de Ciriça au M. ${ }^{\text {quis }}$ de Alanquer". "Ha me mand. ${ }^{\text {do }}$ Su M. ${ }^{\text {d }}$ saver de [V.E] si halla causa su=fiçiente para detener en la prisión a Mos. De la Rabar=diere cabo q. fue de la gente franzesa en el mrañon." En Belen (la torre) a 24 de junio de 1619, $\mathrm{n}^{\text {os }} 34-76$. A.G.S., Estado K (Francia), 1431, A 42. Tambem: "Juan de Ciriça a Gaspar de Sosa sobre lo de Ravardiere”, 22 de junio de 1619. $n^{o s}$ 34-76. AGS, Estado K (Francia), 1431, A 42.

18 "Le M. ${ }^{\text {quis }}$ de Alanquer à Juan de Ciriça", Lisboa 26 de junio de 1619". [Firma: Marquez de Alenquer]. n ${ }^{\text {os } 34-76 . ~ A G S ., ~ E s t a d o ~ K ~(F r a n c i a), ~ 1431, ~ A ~} 42$.

19 "Le $\mathrm{M}^{\text {quis }}$ de Alenquer a $\mathrm{J}^{\mathrm{n}}$ de Ciciça”. "(...) La instancia que haze el Rey de Francia por una persona que conocidamente fue traydor fundado en favorecerle y no en 
castigarle [rabardiere] (...) es que vaya el preso a eccharse a los pies de la princesa nra Señora de cuyas instancias se da muy favorecido (...) Y yo no puedo dilatar lo que manda la infanta de Francia sino por servir mejor a la princesa de españa (...)". AGS, Estado K (Francia), 1477. Lisboa, 25 de enero de 1620.

20 “Al Marques de Alenquer”. 19 de febrero de 1620, A.G.S., Estado (Portugal), 2710.

21 "Le Roi a Inigo de Cardenas", 30 de noviembre de 1613. AGS, Estado (Francia), K 1453, A59.

${ }^{22}$ Sobre seus serviços, ver: "REQUERIMENTO do ex-capitão-mor do Ceará, Martim Soares Moreno, ao rei [D. Filipe II], a pedir ajuda de custo para remediar suas misérias, necessidades e dívidas, tendo em atenção os serviços prestados na conquista e povoamento do Ceará e como capitão-mor na jornada do Grão-Pará”. 1618. Arquivo Histórico Ultramarino, Ceará (avulsos) cx 1, doc. 1. Doravante será citado como: AHU. Moreno permanece durante muito tempo ligado ao governo da Capitania do Ceará, sendo um informante privilegiado também sobre as primeiras atividades francesas e depois holandesas ali. Ver: "REQUERIMENTO do capitão-mor do Ceará, Martim Soares Moreno, ao rei [D. Filipe II], a pedir equiparação do seu ordenado ao do capitão-mor do Rio Grande". Ceará, 6 de março de 1619. AHU, cx 1, doc. 2; "CARTA do capitão-mor do Ceará, Martim Soares Moreno, ao rei [D. Filipe II], a pedir o envio de cinquenta soldados para a construção de uma fortificação". Ceará, 1 de novembro de 1621. AHU, Ceará (avulsos), cx 1, doc. 6.

2328 de mayo de 1615. AGS, Estado (Portugal), 260.

24 "Resumen de lo consultado en lo tocante al Rio Marañon". Valladolid, 4 de julio de 1615. AGS, Estado K (Francia), 1611.

${ }^{25}$ Sobre a atuação de Diego de Cárcamo nas negociações luso-espanholas de 1581, ver: SERRÃO, 1956, p.81.

26 "Do cons" da Fazenda sobre hua petição de Dom Dio de Carcamo g. ${ }^{\text {or }}$ do Maranhão". 4 de fevereiro de 1620. AGS, Secretarias Provinciales, 1474, fl 84; "Responde ao que se lhe escreveu sobre cousas do Maranhao". 4 de abril de 1620, AGS, Secretarias Provinciales, 1552, $f l^{\circ} 128$; “ Cons. ${ }^{\text {ta }}$ sobre hũa petição de dom $\mathrm{Dg}^{\mathrm{o}}$ de Carcamo g. ${ }^{\text {or }}$ do Maranhão". Lisboa, 9 de fevereiro de 1620. AHU, códice 32.

27 "Avis anonyme - Nouvelle de Portugal". 28 (?) de abril de 1621, [sin firma]. AGS, Estado K (de Francia) 1431, A42, ${ }^{\text {os }}$. 116-143.

28 "Carta de Gaspar de Sousa a EL REY em que falla nas differentes materias do governo e da fazenda, e tratta da Conquista do Maranhão, e do modo com que se deve proceder nella, vista estar da sorte que se acha, feita em Olinda a 31 de janeiro de 1615". ABNRJ, vol. 26, pp. 319-20.

29 "Relação do Ceará" [1618]. In: "Documentos para a história de Martim Soares Moreno". Revista do Instituto do Ceará, Fortaleza, vol. XIX (1905), p. 69. Doravante será citado como: RIC.

30 “Jornada do Maranhão por Diogo de Campos Moreno Sargento-Mór do Estado do Brazil”. RIC, tomo XXI, anno XXI (1907), pp. 229-30.

31 "Jornada do Maranhão por Diogo de Campos Moreno Sargento-Mór do Estado do Brazil”, p. 245.

32 Não há consenso nas fontes acerca do número exato de combatentes nativos especificamente envolvidos nesta batalha, ocorrida em 19 de novembro de 1614. Apesar disso as cifras apresentadas são bastante aproximadas entre si, variando sempre entre 
1500 a 2500 índios partidários dos franceses contra cerca de 200 índios aliados dos hispano-lusos. Ver por exemplo: "Para o governador do Brasil". Madrid, 21 de março de 1615, CASGS, doc. 149, p. 254.

33 “Jornada do Maranhão por Diogo de Campos Moreno Sargento-Mór do Estado do Brazil”, p. 236.

${ }^{34}$ Segundo o relatório de Alexandre de Moura, para defesa da região era conveniente que homens como Martim Soares Moreno estivessem a frente das negociações com os nativos. "OFÍCIO do capitão-mor do Maranhão, Alexandre de Moura, ao rei Filipe II, sobre a tomada da fortaleza francesa de São Luís. Faz referências ao estado geral do Maranhão; ao estabelecimento de índios em Tapuitapera; ao reconhecimento de alguns rios e ilhas; à qualidade das terras e à importância do povoamento desta região". Lisboa, 24 de setembro de 1616. AHU, Maranhão (avulsos), cx. 1, doc. 8.

35 “Jornada do Maranhão por Diogo de Campos Moreno Sargento-Mór do Estado do Brazil”, p. 273.

${ }^{36}$ Estava claro, ao menos para algumas autoridades hispano-lusas, que Daniel de La Touche pelo conhecimento acumulado sobre os índios da região era um dos homens mais perigosos para os interesses da Monarquia no extremo Norte da América Portuguesa, mesmo anos depois de sua saída da região. Ver, por exemplo: "Carta del Marques de Alenquer a el Rey sobre los franceses en el Marañon". Firma: Mrz de Alenquer. Lisboa, 11 de fevereiro de 1619”. AGS., Estado K (Francia), 1431, A 42. n ${ }^{\text {os }}$ 34-76.

37 “Jornada do Maranhão por Diogo de Campos Moreno Sargento-Mór do Estado do Brazil", p. 312. Atualizamos a grafia.

${ }^{38}$ Segundo a compilação feita por Diogo de Campos, o artigo estabelece que: "Los señores d'Albuquerque, y de Campos prometten al Señor de la Ravaidière de no tratar alguna cosa com los Salvajes de la isla, ni de Tapitaperá, ni Comat, la qual no sêa tratada por las Lenguas del Señor de la Ravardière, ni los consentirán poder los pies en tierra à menos de díez leguas de sus fortalezas, di de sus puertos, sin la permission del dicho Señor". Rio Marañon, 27 de novembro de 1614, apud CAMPOS MORENO, Diogo de. "Jornada do Maranhão por Diogo de Campos Moreno Sargento-Mór do Estado do Brazil", p. 293.

39 "Materias do Maranhão". Madri, 20 de junho de 1618. AGS, Secretarias Provinviales, 1516, $\mathrm{fl}^{\circ}$. 78 .

40 “Jornada do Maranhão por Diogo de Campos Moreno Sargento-Mór do Estado do Brazil”, p. 258.

${ }^{41}$ Idem, ibidem, pp. 239-40. O principal Diabo Grande também aparece na Relação da missão do Maranhão do jesuíta Luís Figueira. Este padre da Companhia foi recebido por aquele principal na aldeia de Ibiapaba onde esteve cerca de quatro meses (até outubro de 1607), obtendo também informações acerca da atividade francesa na região. FIGUEIRA, 1940, p. 131-32.

42 "Do Cons ${ }^{\circ}$ da Faz sobre Ant ${ }^{\circ}$ de Albuquerq". 2 de mayo de 1620, A.G.S., Secretarias Provinciales, 1474, fls ${ }^{\circ}$ 383-384. Véase también: "Outra sobre Antonio Dalbuquerque, Fidalgo de miha casa filho mais velho de Jeronimo de Albuquerque já falecido, que foi capitão mor da conquista do Maranhao", 26 de agosto de 1620. AGS, Secretarias Provinciales, $1517, \mathrm{fl}^{\circ} 35$. 
43 Entre outros, ver: "Sobre Gaspar de Sousa, 7 de julho de 1623". AGS, Secretarias Provinciales, $1518, \mathrm{fl}^{\circ} .37$

44 "Para sua MAg. ". Com hua petição de Dom D. ${ }^{\circ}$ de Carcomo sobre merce que pede". Pide a el Rey la "comenda das Galveas da Orden de Avis". Lisboa, 16 de mayo de 1620". AGS, Secretarias Provinciales, 1552, $\mathrm{fl}^{\circ} .213$.

45 Por exemplo, sobre a memória dos restauradores André Vidal de Negreiros, João Fernandes Vieira, D. Filipe Camarão, e D. Henrique Dias. Ver: MELLO, 1997, p. 195

${ }^{46}$ Sobre a tomada da Bahia em 1625, conhecida como a "jornada dos Vassalos, ver: SCHWARTZ, 1991, p. 735-762. Sobre a guerra nos trópicos, ver: PUNTONI, 2002. Para uma análise de conjunto sobre as mudanças no modo de fazer a guerra na América Portuguesa, ver: PUNTONI, 2004, pp. 43-66.

\section{REFERÊNCIAS}

ALENCASTRO, Luiz Felipe de. O trato dos viventes: formação do Brasil no Atlântico Sul. São Paulo: Companhia das Letras, 2000.

AMARAL, José Ribeiro do. Fundação do Maranhão. São Luiz: Typografia Teixeira, 1912.

BERREDO, Bernardo Pereira de. Anais Históricos do Estado do Maranhão. São Luís: Alumar, 1988 [1749].

BOXER, Charles. João de Barros. Portuguese humanist and historian of Asia. New Delhi: Concept Publishing Company, 1980.

CARDOSO, Alírio. “A Conquista do Maranhão e as disputas atlânticas na geopolítica da União Ibérica (1596-1626)”. Revista Brasileira de História, v. 31, no 61, 2011, pp. 317-338.

CARDOSO, Alírio. Maranhão na Monarquia Hispânica: intercâmbios, guerra e navegação nas fronteiras das Índias de Castela (1580-1655). Salamanca: tese de doutorado (História) apresentada à Universidad de Salamanca, 2012.

CARDOSO, Ciro F.. Economia e Sociedade em áreas coloniais periféricas: Guiana Francesa e Pará, 1750-1817. Rio de Janeiro: Graal, 1984.

CHAMBOULEYRON, Rafael. "Escravos do Atlântico equatorial. Tráfico negreiro para o Estado do Maranhão e Pará (século XVII e inicio do século XVIII)”. São Paulo: Revista Brasileira de História, v. 26, nº 52 (2006), pp. 79-114. 
CHAMbOUleYRON, Rafael. Portuguese Colonization of Amazon Region, 1640-1706. Cambridge: Tese de Doutorado apresentada à Universidade de Cambridge, 2005.

DAHER, Andréa. O Brasil francês: as singularidades da França Equinocial, 16121615. Rio de Janeiro: Civilização Brasileira, 2007.

FIGUEIRA, Luís. "Relação da missão do Maranhão [1608-1609?]”. In: LEITE, Serafim. Luiz Figueira, sua vida heróica e sua obra Literária. Lisboa: Agência Geral das Colônias, 1940, pp. 131-32.

FORNEROD, Nicolas. São Luis, sur la France Équinoxiale. São Luis: Alliance Française/Academia Maranhense de Letras, 2001.

KANTOR, Iris. "Usos Diplomáticos da Ilha Brasil. Polêmicas cartográficas e historiográficas". Vária História, vol. 23, no 37 (Belo Horizonte, janeiro-junho, 2007): $70-80$.

LACROIX, Maria de Lourdes Lauande. A fundação Francesa de São Luis e seus mitos. $2^{a}$ edição. São Luis: Lythograf, 2002.

MELLO, Evaldo Cabral de. Rubro Veio: O Imaginário da Restauração Pernambucana. Rio de Janeiro: Topbooks, $2^{\text {a }}$ edição, 1997.

MEIRELLES, Mario Martins. França Equinocial. São Luís: SECMA/Civilização Brasileira, 1982.

MONTEIRO, John M. “Tupis tapuias e historiadores: Estudos de História indígena e do indigenismo". Campinas: Tese de Livre Docência (história) apresentada à Universidade Estadual de Campinas, 2001.

MOTA, Antônia da Silva \& Mantovani, José Dervil. São Luis do Maranhão no século XVIII: a construção do espaço urbano sob a lei das Sesmarias. São Luís: Edições FUNC, 1998.

PEREZ-MALLAINA, Pablo Emilio. "La Carrera de Indias: inconvenientes y ventajas del sistema español de comunicaciones transatlánticas”. In: VENTURA, Maria da Graça. (Eds) Viagens e Viajantes no Atlântico quinhentista. Lisboa: Edições Colibri, 1996. 
PIANZOLA, Maurice. Os Papagaios Amarelos: os franceses na conquista do Brasil. São Luís: SCEM/Alhambra, 1992.

REIS, Arthur Cézar Ferreira. Limites e demarcações na Amazônia brasileira. A Fronteira com as Colônias Espanholas, vol. 1. Belém: Secult, 1993.

SCHWARTZ, Stuart. "The Voyage of the vassals, royal power, noble obligations, and merchant capital before the Portuguese Restoration of the independence, 1624-1640". The American Historical Review, vol. 96, no 3 (junho, 1991), pp. 735-762.

SERRÃO, Joaquim Veríssimo. O reinado de D. António Prior do Crato (1580-1582), vol. 1. Coimbra, 1956.

SOUTHEY, Roberto. História do Brazil, tomo segundo. Rio de Janeiro: Livraria de B.L. Garnier, 1862.

PUNTONI, Pedro. A Guerra dos Bárbaros: povos indígenas e a colonização do sertão nordeste do Brasil, 1650-1720. São Paulo: Edusp/FAPESP/Hucitec, 2002.

PUNTONI, Pedro. "A arte da guerra no Brasil: tecnologia e estratégia militares na expansão da fronteira da América portuguesa (1550-1700)”. In: Castro, Celso; IZECKSOHN, Vitor; Kraay, Hendrik. Nova História Militar Brasileira. Rio de Janeiro: FGV, 2004, pp. 43-66. 